Archiv für die gesamte Virusforschung 41, 143-146 (1973)

(C) by Springer-Verlag 1973

\title{
A New Genetic Marker for Influenza Virus Subunits
}

\author{
Brief Report
}

\author{
By \\ TaM. S. David-WEST ${ }^{1}$ \\ Department of Bacteriology, University College Hospital Medical School, \\ London, England \\ With 3 Figures
}

Received November 22, 1972

Several recombinant strains of influenza virus are produced in which the two virus-coded subunits, haemagglutinin (HA) and neuraminidase (Ndase) are derived from the respective parent strains. These studies in addition to suggesting the basis for the natural emergence of new strains of influenza virus (6) also have practical application in vaccine production (3).

Various markers have been used to characterize these recombinants and their parents (4); these include thermal stability of the $H A$, differential susceptibility to non-specific inhibitors, rate of elution from erythrocytes, virulence in reference hosts, plaque type and/or plaque morphology, virion morphology (spherical or filamentous), and surface antigens including Ndase. Most of these tests are cumbersome to perform, and are liable to variation. On the other hand, a number of these tests are applicable to only limited number of strains of influenza virus. In the course of a detailed study of the effect of guanidine hydrochloride on several strains of influenza virus (DAVID-WEST and BELYAVIN, in preparation) a striking differential effect of the compound on the viral haemagglutinin and neuraminidase activities was consistently observed. The genetic significance of this was later tested, using different sets of parent-recombinant combinations. The results of these experiments are reported in this communication.

Three recombinants were used: X-7 (F1), a hybrid of $A_{0} / \mathrm{NWS}$ and $A_{2} / \mathrm{R} 15$, having the Ndase antigen of the $A_{2}$ parent and the $H A$ antigen of the $A_{0}$ parent (5); X-31, having both Ndase and HA derived from $\mathrm{A}_{2} / \mathrm{Hong} \mathrm{Kong} / 68$, but with the soluble ( $S$ ) antigen from $A_{0} / \operatorname{PR} 8$ (3). The third is a recombinant between $A_{0} /$ $\mathrm{BEL} / 42$ and $\mathrm{A}_{2} /$ Singapore/57; the $\mathrm{HA}$ derived from the former parent and the Ndase from the $A_{2}$ parent (7). All the strains were kindly provided by Dr. G. C. Schild, World Influenza Centre, National Institute for Medical Research, Mill Hill, London.

1 Visiting Research Worker from the Virus Research Laboratory Faculty of Medicine, University of Ibadan, Ibadan, Nigeria. 
The viruses were grown in the allantoic cavity of 10 or 11-day-old embryonated hens eggs, and were purified by differential centrifugation, followed by rate zonal centrifugation through a linear $(10-50 \%)$ sodium glutamate gradient in Trissaline, $\mathrm{pH} 7.5$.

Guanidine hydrochloride (Sigma Grade 1) was prepared in Tris-saline and mixed with virus to give final molar concentrations of $0.5,1.0$ and 1.5 . The virusguanidine mixtures were maintained at $37^{\circ} \mathrm{C}$ in a water bath for 30 minutes. After stopping the reaction by chilling in crushed ice, followed by dilution in buffer, the residual haemagglutination and neuraminidase activities were determined.

Haemagglutinin was assayed by the microtitre method using Takatsy loops. Equal volumes of freshly prepared $0.5 \%$ fowl red blood cells suspension were added to the virus dilutions, and the test read after $30-45$ minutes at room temperature $\left(20^{\circ}-22^{\circ} \mathrm{C}\right)$.

Neuraminidase assays were performed by mixing virus with collocalia mucoid substrate in $0.02 \mathrm{M}$ sodium acetate buffer, $\mathrm{pH} 6.0$, in $0.15 \mathrm{M}$ sodium chloride. The mixtures were incubated overnight at $37^{\circ} \mathrm{C}$, and the free sialic acid released assayed by the Aminoff method (1). All tests were set up in duplicate, and repeated at least three times.

The results obtained with the three hybrids and corresponding parent strains are summarized in the diagrams (Figs. 1, 2 and 3) as per cent residual HA or

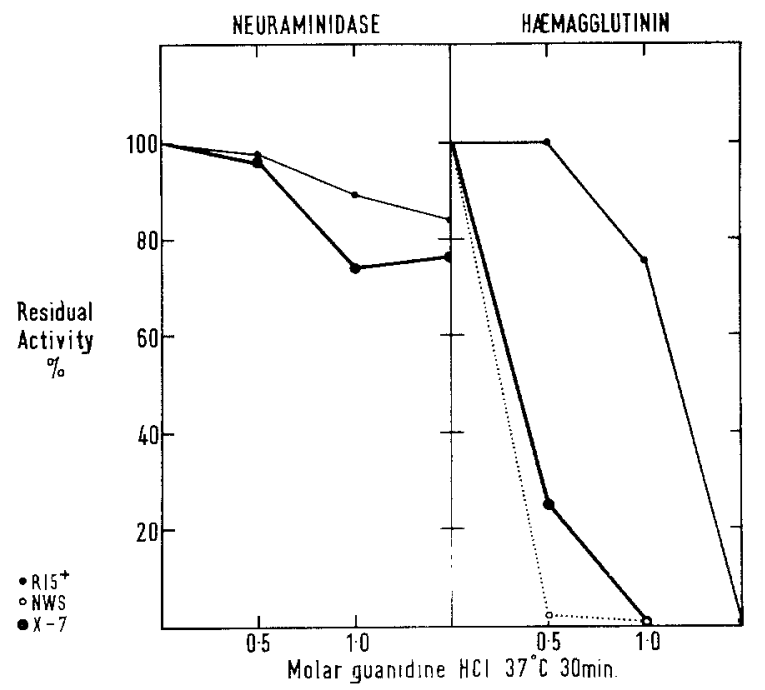

Fig. 1. Guanidine hydrochloride inactivation kinetic curvos of influenza virus X-7 ( $F 1$ ) and its corresponding parent influenza virus strains. Note: Under the conditions of the experiment the neuraminidase of strain NWS was inactive. This is in accord with the observation of BuRNer (1951)

Ndase activity remaining after 30 minutes following exposure to the corresponding guanidine molarity at $37^{\circ} \mathrm{C}$. The residual activity is proportional to the rate of inactivation, assuming approximately equivalent kinetics over the relevant period of measurement. It is evident from the data that: (i) The haemagglutinin and neuraminidase of an influenza virus strain each has a demonstrable inactivation "profile" following exposure to varying concentrations of guanidine hydrochloride. 


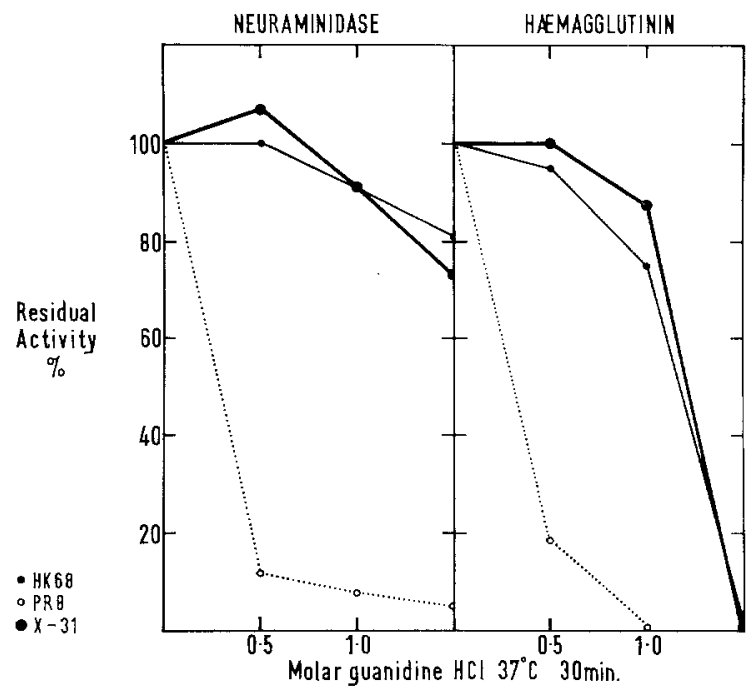

Fig. 2. Similar inactivation kinetic curves for influenza virus $\mathrm{X}-31$, and its corresponding parent strains

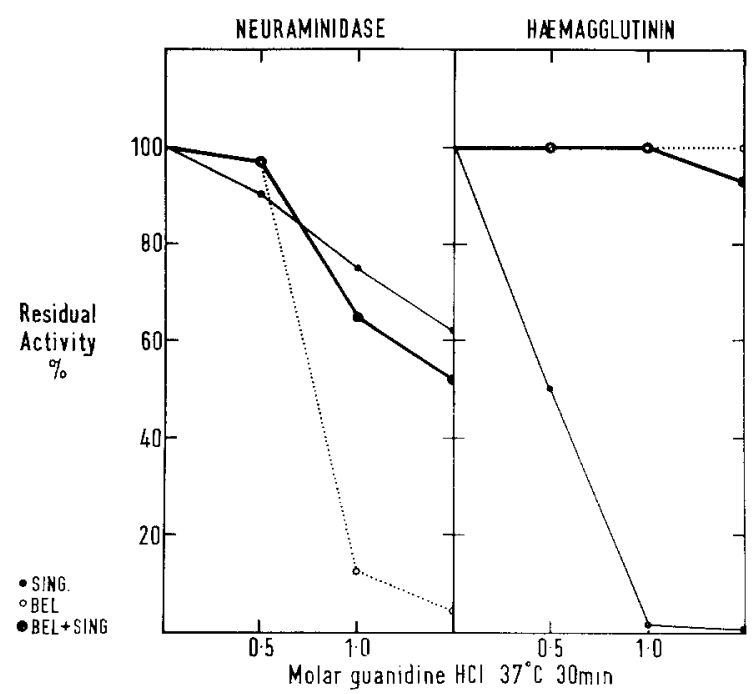

Fig. 3. Similar inactivation kinetic curves for influenza virus hybrid BeL + SING.Apore, and its corresponding parent strains

(ii) The "profile" concerned is determined by the viral genome, as the characteristic response of a parent virus strain in the case of either haemagglutinin or neuraminidase is likely to be retained in a hybrid strain.

In so far as observation (ii) above were to be generally true among influenza virus strains, the implication would be that biological activity in the case of both haemagglutination and neuraminidase activity was dependent upon specific intra-molecular configurations, which are sensitive to inactivation by guanidine. On this basis, some broad relationship between guanidine inactivation kinetics 
and antigenic specificities may be expected. Detailed work along these lines are in progress.

The tests for the guanidine hydrochloride (GH) marker described here could thereby complement the conventional serological tests at present commonly used in influenza virus hybridization studies. Because the tests for the GH marker are easy to perform, and need fewer reagents, they can be used readily to monitor the efficiency of recombination at various stages of the hybridization process. Furthermore, there are indications that the tests could have broader application in influenza virus typing.

\section{Acknowledgment}

I wish to thank Professor G. Belyavin for helpful discussion and continued interest throughout this study.

\section{References}

1. Aminoff, D.: Method for quantitative estimation of $\mathrm{N}$-acetylneuraminic acid and their application to hydrolysates of sialomucoids. Biochem. J. 81, 384-392 (1961).

2. Burnet, F. M.: A genetic approach to variation in influenza viruses. 1 . The characters of three substrains of influenza virus A (WS). J. Gen. Microbiol. 5, 46-53 (1951).

3. Kilbourne, E. D.: Future influenza vaccines and the use of genetie recombinants. Bull. WldHlthOrg. 41, 643-645 (1969).

4. Krlbodrne, E. D.: Influenza virus genetics. Progr. med. Virol. 5, 79-126 (1963).

5. Kilbourne, E, D., F. S. Lief, J. L. Schulman, R. I. Jahiel, and W. G. Laver: Antigenic hybrids of influenza viruses and their implications. Perspect. Virol. 5, 87-106 (1967).

6. LAVer, W. G., and R. G. Webster: Studies on the origin of pandemic influenza. II. Virology 48, 445-455 (1972).

7. Schild, G. C., D. McCahon, and A.P. Kendal: Immunological and structural studies on a recombinant influenza A virus. In: The Biology of Large RNA Viruses: (RICHaRd D. Barry and Brian W. J. MAHY, eds.) p. 638. Academic Press, 1970.

Author's address: Dr. TAM. S. David-West, Virology Division National Institute for Medical Research, Mill Hill, London NW7 1 AA, England. 